\title{
Covariant Factors of Activity-Oriented Curriculum Operation in Cooperative Learning Effectiveness
}

\author{
Shyh-Bao Chiang ${ }^{1}$ \\ ${ }^{1}$ Department of Visual Communication Design, National Yunlin University of Science and Technology, Taiwan, \\ R.O.C. \\ Correspondence: Shyh-Bao Chiang, Department of Visual Communication Design, National Yunlin University of \\ Science and Technology, 123 University Road, Section 3, Douliou, Yunlin 64002, Taiwan, R.O.C. Tel: \\ 886-5-534-2601\#6218. E-mail: chiangsb@yuntech.edu.tw \\ Received: July 1, 2021 \\ doi:10.5430/irhe.v6n2p21 \\ Accepted: July 21, 2021 \\ Online Published: July 30, 2021 \\ URL: https://doi.org/10.5430/irhe.v6n2p21
}

\begin{abstract}
The purpose of this study is to explore the operation of an activity-oriented curriculum. Class members were grouped by their majors to complete an academic seminar together and fill in the evaluation for the two variables of cooperative learning and participation attitude, so that this study could explore the relationship between covariate factors for cooperative learning effectiveness. The subjects of this study are the master students in the Department of Visual Communication Design of a university of science and technology in central Taiwan. The course is a required course seminar. In order to properly arrange the manpower, the nominal variables in research design were formed by grouping through professional division of labor. The research tools include cooperative learning evaluation and participation attitude evaluation. The data were obtained through the questionnaire about the two variables. The two-factor covariate analysis was used to test the hypothesis. The results showed that the cooperative learning effectiveness did not vary according to the grouping type when the co-variable interference of participation attitude was excluded. It was found that the academic group had the best evaluation among all groups. Therefore, it was concluded that the students in the master class, due to their mature mental development, were generally able to put themselves in the membership's position and pay attention to team efficiency in the learning environment of team cooperation, so as to gather the centripetal force from the group to the whole class, and jointly complete the task assigned by the course. Among the groups, the academic group had few members but heavy works. Due to proper division of labor, they completed the task on time, and the experience of being responsible for the administrative processing of the academic paper was profound, which led to the best evaluation of the cooperative learning effectiveness. Due to limited number of members, this study also received many suggestions during the review meetings, which aided in facilitating successful implementations of the subsequent course activities and enabling students to gain practical experiences from this activity.
\end{abstract}

Keywords: activity orientation, curriculum design, cooperative learning, participation attitude, class organization

\section{Introduction}

\subsection{Research Background}

Teaching is implemented through the class organization. The efficiency of management and the effectiveness of curriculum activities depend on the interaction between teachers and students, as well as the enthusiasm of peers for learning. In order to complete the learning of knowledge and skills, cooperative learning enables learners to achieve learning tasks through specialization, and highlights the characteristics of members. Therefore, an individual's attitude towards the course participation may affect the cooperative outcome. In addition, although the focus of education assessment is on individual effectiveness, some of the operational situations involve peer-to-peer collaborative learning in the form of groups in response to the operational style of the workplace (Suo and Ren, 2006). For this reason, teachers try to project problems or tasks in real situations in the hope of the learners' putting themselves in the situation, jointly conceiving solutions and simulating the handling process. In fact, this is the accumulation of practical experience (Chang et al., 2017), and the process of applying problem-oriented concepts to cooperative learning. However, when teachers used collaboration in group learning, students' reactions were polarized. Some of them believed that the curriculum was well-conceived whereas the implementation was 
unsatisfactory. It might be mainly related to the interaction among group members (Chiang, 2015). Moreover, because this type of interpersonal interaction can affect the attitude and willingness of students to participate, the effectiveness of learners' participation in a cooperative learning environment still depends on the degree of individual willingness, and the degree of influence of participation attitude has become the focus of this study.

\subsection{Motives and Purposes}

Taiwan students are accustomed to the independent learning mode, and there is much to be improved in activity-oriented cooperative learning. Being a teacher, the researcher tried to apply the activity-oriented curriculum planning to the master class and understand whether the participation attitude of students affects the cooperative learning effectiveness through the execution of activities in real situations and the actual fields. Therefore, the purposes of this study are as follows:

1) To understand the class's activity patterns and attitudes towards cooperative learning.

2) To clarify the co-variable relationship between cooperative learning and participation attitude.

3) To understand the influence of grouping categories on cooperative learning effectiveness after excluding the participation attitude factor.

\section{Literature Review}

\subsection{The Relationship Between Cooperative Learning and Participation Attitude}

In addition to increasing students' learning motivation, teachers' application of multiple teaching methods in the curriculum can help to discover the characteristics of each individual student through the evaluation on every aspect. The cooperative learning method helps students to learn from each other, and helps in developing the spirit of teamwork. Wang (2016) considered that the cooperative learning teaching can stimulate students' interest in classroom participation, make them willing to learn actively, and enhance learning effectiveness through cooperative participation. Cheng et al. (2014) mentioned that the curriculum design of cooperative learning emphasized cooperation among members of a group. In theory, if students are distributed in a heterogeneous way, students with different attributes are mixed into a group, and each of them can play an effective role by complementation of expertise in producing greater learning effect. In addition, according to Su and Chen (2007), cooperative teaching method uses group atmosphere and organizational identity to promote mutual assistance and mutual benefit among team members, so that all learners can feel the benefits of cooperation and achieve learning efficacy (Kao, 2012; Wu, Nian, 2021). Therefore, from the perspective of students' learning, it is the formation of more benign interaction among group members that positively creates a heated atmosphere in the classroom and helps students to focus on the course learning.

In addition, cooperative learning is mainly based on the needs or limitations of the classroom, and group learning enables the team to set up homogeneous or heterogeneous strategies with limited manpower (Hu et al., 2021). Kao (2003) mentioned that students in a class were mainly divided into array heterogeneous and homogeneous groups in cooperative learning according to nominal categories such as gender and ability. In the group, members complete the task of the course unit through division of labor and cooperation to experience the learning result. Therefore, good class organization and management is an important factor for the success of cooperative learning. Relatively, cooperative learning can strengthen the learning efficacy of students and achieve the set goal of the class in the course. Chang and Lin (2016) listed cooperative learning as a necessary teaching method in their research on the implementation of problem-oriented learning. They emphasized that students' learning evaluation projects should be developed to observe the development of students' personality traits in cooperation and cultivate their gregarious attitude in accordance with the organizational form of the workplace. It is obvious that cooperative learning is the normal operation of social specialization. Moreover, the teaching strategies of cooperative learning are not limited by the categories of majors.

The operation and effectiveness of cooperative learning depend on learners' attitudes and willingness to participate (Le Bail et al., 2020). Keyon (1968) defined an individual's attitude as a relatively complex implicit cognitive trait that cannot be observed and produces varying degrees of response to a particular goal. Participation can be observed by individuals' involvement in group activities, and members of the group achieve the expected motivation through interaction. In other words, participation is an essential behavior of individual learning (Wenger, 1998). Chou (2018) stated that the participation attitude of students in learning in colleges and universities can be positively improved through appropriate curriculum planning and teaching methods, and the use of class operation. This is supported by the study of Cheng (2002), which concluded the importance of group organization and obtained the influential relationship among factors. According to this study, a learning field is a group unit composed of classes, and most of 
the academic affairs and class affairs are mostly decided and formulated by the group. Therefore, teachers should use teaching methods to strengthen students' centripetal force and sense of belongingness to the class, and use teamwork learning strategies to strengthen group identity. These psychological factors affect members' willingness to participate in class learning activities and individual evaluation.

\subsection{Class Organization and Curriculum Activity Learning}

Class is a unit of the teaching field and a system of learning styles aiming at organizational learning. Rui (2013) considered that class is an organization that implements management function, enables the group to produce operational efficiency, and helps all members to develop continuously in a specific direction. There are formal and informal organizations in a class. The formal organization is managed by the traditional class meeting, while the informal organization is established based on the task. Informal organization refers to a group that, due to certain factors, tasks or activities, requires members with certain characteristics to form a management and operation structure. There are no restrictive provisions or clear rights and obligations for its composition. It is mainly based on the scope of the class activity, and the group forms values and interests together. Specific implementation activities are used to complete the set tasks (Meng, 2011). The common places among the two organizational types mentioned above are that all members are involved in the organizational structure. The mentors are mainly responsible for the work situation of all class members if they choose to participate. The group leader is responsible for the work within the group organization, and the group members are responsible for their assigned tasks or work (Zhou and Luo, 2010). The organizational structure of such groups is just like the microcosm of social organizations. Members learn the operation skills by playing a role in the small society of the class and adapt to the future social structure from the operation of the organization. Moreover, the professional, management and interpersonal experience they gain from this activity are something they do not learn from their majors.

The informal organization has an active organization structure which requires the creation of tasks and activities to make the class organization to generate motivations and accumulate preset learning gains through participation and experience (Uzun et al., 2020). In other words, informal organization is generated because of tasks and groups work out a plan of activities to jointly complete the goal. This intention process is to implement specific strategies to achieve preset goals in the curriculum. For the abnormal curriculum design, Taba (1962) mentioned that curriculum design is a procedure to construct curriculum content and organize the context between these contents. Chiu (2003) explained that the message conveyed by the curriculum "activities" is that students are expected to complete the activities planned by the teacher, exhibit good behavior, and use mental thinking and reflection. From the evaluation of teachers' teaching strategies, activity methods and implementation can indeed influence students' learning effectiveness (Kuo, 2000), among which, the interaction of peer learning is relatively significant. According to the research of several scholars, most classroom activities are related to group behaviors. In the integrated curriculum activities, the project study is not only a typical group communication learning model course, but also a professional learning-oriented activity task. This construction is based on the problem-oriented course operation, in which students develop learning motivation, and accumulate personal experience and interest (Chang, 2016). Therefore, the implementation of curriculum activities is based on the management needs of the organization. Through informal class grouping, the actual simulation of the society in the learning field can be achieved.

\subsection{Summary}

This study attempted to understand the relationship between members' participation attitudes and the cooperative learning effectiveness after the implementation of curriculum activities through task grouping learning in class professional organizations. From the point of view of teachers, class organization should be established, curriculum activity planning and execution should be involved, so that the self-disciplined group can be gradually formed, and formal constraints can be gradually internalized into class identity and cohesion (Huang, 2011). Teachers expect the group members to have respective roles and tasks, experience class management through professional organizations, and feel empathy, in order to stimulate the degree of positivity, and improve the attitude of participation in learning (Wu, 2015). Based on the literature mentioned above, it is recognized that learners' attitudes towards the participation in course activities may be an influencing factor of cooperative learning effectiveness, which is the orientation of this study.

\section{Research Method}

\subsection{Research Variables and Course Description}

This study mainly discussed the hypothesis that the group of students participating in the class is a nominal variable under the implementation of curriculum activities. Based on the division of responsibilities in cooperative learning, 
the roles, specific tasks and coping mentality of class members in the activities were confirmed, which were reflected in the team cooperation experience and feelings. This study also tried to understand the influence of specific responsibilities on the evaluation of cooperative learning after removing the effect of participation attitude. The study architecture description is shown in Figure 1. Moreover, the activity was introduced into the seminar course. The class form was mainly based on the problem-orientated structure, so that students could carry out the academic seminar and design camp which were regularly held by the department all year round according to the course planning. Based on the experience of previous seminars held by the department, the members organized their work according to the nature of tasks, solicited papers, recruited students and invited lecturers. The planning concept of this course is to reduce traditional forms of teaching and let all members of the class learn by doing so as to implement Dewey's educational philosophy in action (Mosleh, Larsen, 2020). In a course activity, there are many uncertain factors and problems that need to be discovered, discussed and solved by the students involved. Therefore, the blueprint planning and operation of the course should be more flexible. Learners' learning effectiveness involves not only the flexible use of academic knowledge, but also the accumulation of experiences of successful or failed executions.

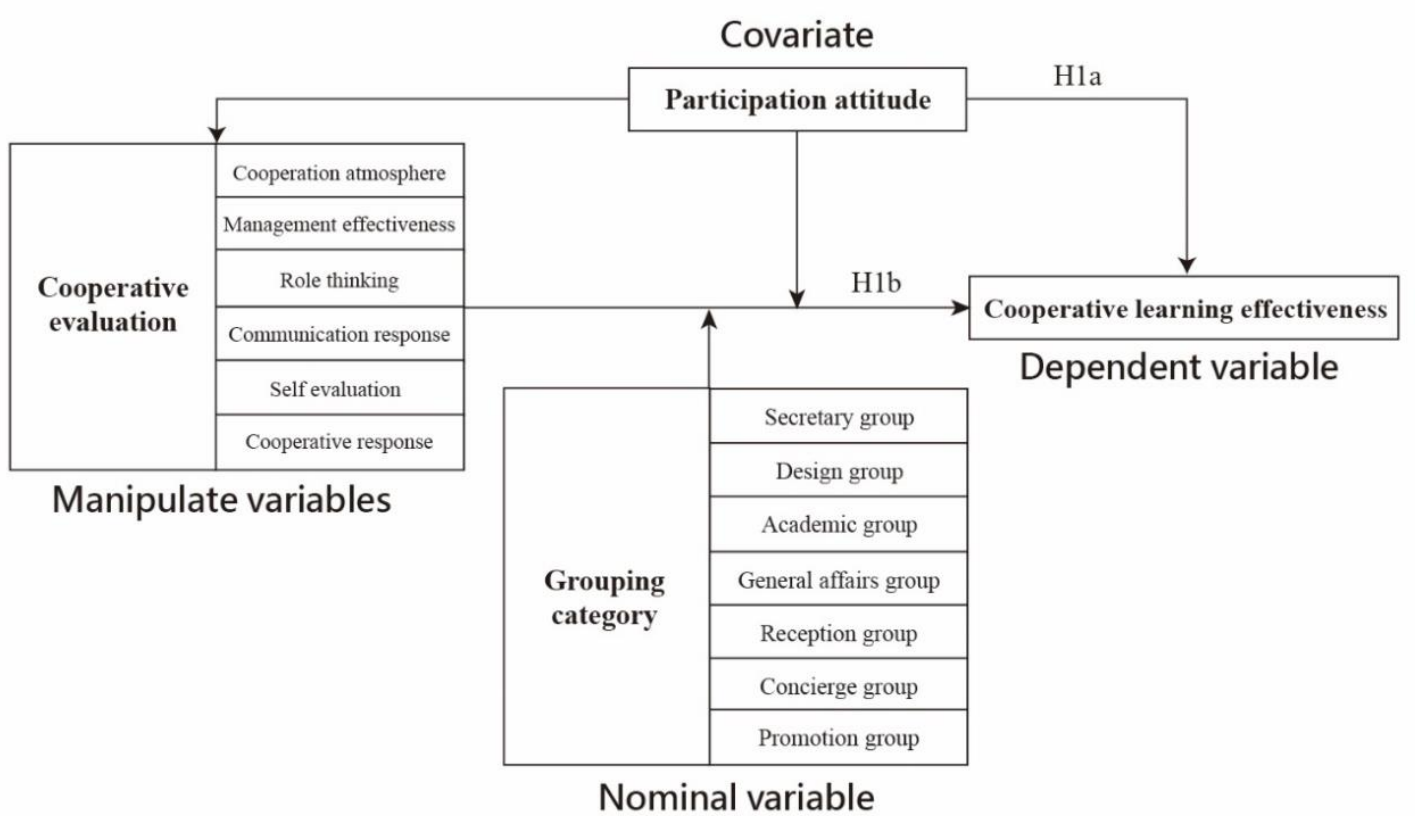

Figure 1 . The variable architecture diagram of this study (drawn by this study)

\subsection{Research Subjects}

The students needed to be grouped according to tasks, so the operating variable of this study was formed. The following is a brief description of group categories. The secretary group assisted the instructor in designing and formulating the work before the seminar, and communicated internally with the group leaders to supervise their work. The clerical group was mainly responsible for the visual design of this event, making relevant publicity materials and contacting manufacturers. The academic group assisted in the management of the online submission system, the contact between the authors and the reviewers, the reply of community messages, and the revision and notification of the paper format. The conference group was responsible for the site layout, hosting, venue control, video recording and broadcasting and catering arrangement. The reception group was responsible for the contact of foreign guests in advance, reception and transportation during the event. The concierge group, which was similar to the reception group in nature, focused on the work of participants, authors and commentators on the day of the seminar. The promotion group was responsible for assisting the clerical group in event information promotion, message editing and event marketing.

\subsection{Research Tool}

The questionnaire was modified based on the framework of Tang's (2012) Cooperative Learning Questionnaire, and 
the evaluation of the validity of the questionnaire in this literature was referred to. The composition of variable architecture focused on the organization which was based on group cooperation. Members may be involved in the interaction between people, things, places, things or situations, and the cooperative feelings formed through personal experiences and experience accumulation. Nominal variables in the research design were mainly confirmed and selected through literature collation, which has a certain degree of correlation. Team cooperation is widely used in teaching in Taiwan, so that students can experience the training focus through the division of labor, management, interpersonal interaction, and problem solving. Therefore, the questionnaire and literature collection were used as tools to obtain students' feedbacks. The five-point Likert Scale was adopted to evaluate individual cognitive feelings and attitudes related to the contents of the items. Among them, field 1 represents the lowest degree of agreement, and field 5 represents the highest degree of agreement. The respondents responded to the items one by one. It conforms to the omission mechanism of the questionnaire design.

Second, in terms of questionnaire content, the Cooperative Learning Assessment Questionnaire consists of six dimensions, with a total of 53 items, including eight items of cooperative atmosphere, 10 items of efficiency management, 10 items of role thinking, seven items of communication response, 10 items of self-evaluation, and eight items of cooperative spirit. In terms of the operational definition of each dimension, the cooperative atmosphere is mainly used to understand the invisible atmosphere formed by team interaction. Efficiency management is used to understand whether there is a clear management system, reward and punishment in the team. Role thinking is used to understand various aspects of work or interaction from the perspective of teammates, and examine whether they have an empathic view. Communication response is used to test the communication attitude of each team in the working situation. Self-evaluation is used to understand the individual evaluation of the members in team learning after the implementation of the activity. Cooperative spirit is used to understand the gains of participants for cooperative learning.

Then, this questionnaire was pretested by the TA and some students. In reliability evaluation, internal consistency analysis was employed to test the reliability, and the overall reliability coefficient was. 982 . The reliability coefficient of each dimension was between .881 and .922 , which fell in the high standard of the reliability value for questionnaire. The internal consistency can be adopted as one of the factors to construct the validity evaluation of the variable questionnaire of Cooperative Learning Assessment (Wang, 2015).

\subsection{Execution Steps}

The test was carried out in the 9th week of the seminar course, which was after the completion of seminar. The researcher came into the class and chaired a focus group meeting, and held a joint post-meeting review with students from two classes. To avoid interference with the completion of the questionnaire, the questionnaire was completed prior to the start of the review meeting. Before students filled in the questionnaire, researchers explained the topic of the questionnaire, the items, and other contents, and then asked students if they had any question. After confirming that they understood everything correctly, the students started to fill in the answers. The questionnaire was completed through the cloud form of the online questionnaire platform with the QR Code pattern linked to the webpage. Students scanned the QR code with smart phones to enter the questionnaire website. In principle, there is no time limit for filling in the answers, and the time spent by all members is about 40 minutes. After all the members completed the questionnaire, all data were uploaded to the cloud database in real time, and the researchers downloaded the complete data. After the file format was converted by software, SPSS was adopted in reading the data, and the report setting of the first stage was started. The figures of each dimension were summed up to form the average value of the dimension, and the total average value of the variable was calculated to complete the sorting of basic descriptive statistics. Then, inferential statistical hypothesis processing was carried out, and the ANCOVA test was adopted. Data tables included the homogeneity test of regression coefficients within the group and the comparison between the evaluation values of covariate parameters and the program pairs were output successively. After obtaining the set data, relevant values were copied into the verification summary table one by one. Finally, according to the hypothetical project, the chart was sorted into the text for an auxiliary explanation, and the results were written down after completing all steps.

\section{Research Results}

\subsection{Homogeneity Test of Intraclass Regression Coefficients}

Before the covariate analysis, it is necessary to test the homogeneity hypothesis of the intraclass regression coefficients to understand whether the slope of the covariate is the same as that of the dependent variables in the regression analysis in this study. According to Wang (2015), if the covariate is taken as one of the independent variables, it is to test whether the independent variable and the covariate have significant differences in the 
interaction terms. If it reaches a significant level, it indicates that the homogeneity hypothesis of the intraclass regression coefficients is not supported. As can be seen from the verification of effect items between subjects in Table 1, the total average interaction term of independent variable group category and covariate participation attitude has an F-value of .080 and P-value of 0.971 , not reaching the significant level of 0.05 . The results show that the relationship between the covariate participation attitude and the dependent variable cooperative learning effectiveness does not vary with different processing conditions of the independent variable. In other words, the regression analysis of the covariate participation attitude and the dependent variable cooperative learning effectiveness has almost the same slope.

Table 1. Homogeneity Test of intraclass regression coefficients

\begin{tabular}{lcrrrr}
\hline Source & $\begin{array}{c}\text { Type III sum of } \\
\text { squares }\end{array}$ & df & $\begin{array}{r}\text { Mean sum } \\
\text { of squares }\end{array}$ & F & P \\
\hline Model & $752.584 \mathrm{a}$ & 11 & 68.417 & 351.445 & .000 \\
Groups of operating & 2.153 & 4 & .538 & 2.764 & .046 \\
Average participation attitude & .074 & 1 & .074 & .383 & .541 \\
$\begin{array}{l}\text { Groups of operating * Average } \\
\text { participation attitude }\end{array}$ & .047 & 3 & .016 & .080 & .971 \\
Error & 5.840 & 30 & .195 & & \\
Total & 758.424 & 41 & & & \\
\hline
\end{tabular}

a. $\mathrm{R}$-square $=0.992$ (R-square after adjustment $=0.989)$

\subsection{Covariate Analysis}

The main purpose of this study was to test whether there is a significant difference between the individual mean and the total mean between the seven groups of operating variables after controlling the influence of participants' participation attitude on cooperative learning. The results of the report are shown in the summary table of covariate analysis in Table 2. When the covariate participation attitude on cooperative learning is removed, the variation value F-value is 1.725 and $\mathrm{P}$-value is 0.146 , which does not reach the significance level of 0.05 , indicating that the subjects' self-evaluation of cooperative learning is not affected by the professional attribute of the grouping category. On the contrary, the F-value of participation attitude is 22.129 and the P-value is 0.000 , which indicates a significant difference. Therefore, a post-event comparison is conducted to understand the influence of the covariate on grouping categories, which can be used as a reference for subsequent conclusions.

Table 2. Covariate analysis summary table

\begin{tabular}{lccccc}
\hline \multicolumn{1}{c}{ Source } & SS & df & MS & F & Post hoc \\
\hline Covariate & 3.948 & 1 & 3.948 & $22.129^{* * *}$ & \\
Groups of operating & 1.846 & 6 & .308 & 1.725 & \\
SSa & & & & & \\
Error SSs/a & 5.887 & 33 & .178 & & \\
\hline
\end{tabular}

$* \mathrm{p}<.05 \quad * * \mathrm{p}<.01 \quad * * * \mathrm{p}<.001$

The homogeneity hypothesis of the intraclass regression coefficients was supported by empirical evidence, which indicated that there was no difference in the regression coefficients of each grouping category. Therefore, the common values of the intraclass regression were allowed to be used as a substitute. Table 3 shows that the common value of intraclass regression coefficients is 4.704 , and the estimated value of $95 \%$ confidence interval is between .334 and .879 . 
Table 3. Estimated parameter values of each grouping category

\begin{tabular}{|c|c|c|c|c|c|c|}
\hline \multirow{2}{*}{ Parameter } & \multirow{2}{*}{$\begin{array}{l}\text { Estimated } \\
\text { value of } B\end{array}$} & \multirow{2}{*}{$\begin{array}{l}\text { Standard } \\
\text { error }\end{array}$} & \multirow{2}{*}{$\mathbf{t}$} & \multirow{2}{*}{$\mathbf{P}$} & \multicolumn{2}{|c|}{$\begin{array}{l}95 \% \text { confidence interval } \\
\text { of the difference }\end{array}$} \\
\hline & & & & & Lower & Upper \\
\hline Intercept & 1.675 & .527 & 3.176 & .003 & .602 & 2.747 \\
\hline $\begin{array}{l}\text { Average participation } \\
\text { attitude }\end{array}$ & .588 & .125 & 4.704 & .000 & .334 & .843 \\
\hline$[2=$ Design group $]$ & .383 & .335 & 1.144 & .261 & -.298 & 1.065 \\
\hline$[1=$ Secretary group $]$ & -.020 & .317 & -.063 & .950 & -.665 & .625 \\
\hline [6= Reception group $]$ & .189 & .166 & 1.139 & .263 & -.149 & .528 \\
\hline$[7=$ Promotion group $]$ & -.011 & .437 & -.025 & .981 & -.900 & .879 \\
\hline [3= Academic group $]$ & .806 & .266 & 3.035 & .005 & .266 & 1.347 \\
\hline [5= Concierge group $]$ & .132 & .203 & .650 & .520 & -.282 & .546 \\
\hline $\begin{array}{l}{[4=\text { General affairs }} \\
\text { group }]\end{array}$ & $0 \mathrm{a}$ & . & . & . & . & \\
\hline
\end{tabular}

a. Since this parameter is repeated, it is set to zero.

According to Table 4, the adjusted average value of the cooperative learning effectiveness of the seven groups is 4.501 for the clerical group, 4.097 for the secretary group, 4.307 for the concierge group, 4.107 for the promotion group, 4.924 for the academic group, 4.250 for the reception group, and 4.117 for the conference group. In the covariate analysis, the covariate effect is deducted first, and then the significance of the effect on the independent variable is tested. Therefore, in the post-comparison, subsequent processing is conducted according to the corrected average value of each group according to the dependent variable (Wang, 2015).

Table 4. Estimated value of each grouping category

\begin{tabular}{|c|c|c|c|c|c|c|c|c|}
\hline \multicolumn{2}{|c|}{ Groups of operating } & 2 & 1 & 5 & 7 & 3 & 6 & 4 \\
\hline \multicolumn{2}{|c|}{ Average } & $4.501^{\mathrm{a}}$ & $4.097^{\mathrm{a}}$ & $4.307^{\mathrm{a}}$ & $4.107^{\mathrm{a}}$ & $4.924^{\mathrm{a}}$ & $4.250^{\mathrm{a}}$ & $4.117^{\mathrm{a}}$ \\
\hline \multicolumn{2}{|c|}{ Standard error } & .317 & .299 & .129 & .425 & .244 & .174 & .106 \\
\hline \multirow{2}{*}{ 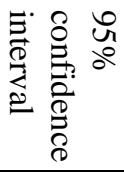 } & Lower & 3.856 & 3.488 & 4.045 & 3.243 & 4.428 & 3.897 & 3.903 \\
\hline & Upper & 5.145 & 4.706 & 4.569 & 4.971 & 5.420 & 4.603 & 4.332 \\
\hline
\end{tabular}

As shown in Table 5, the difference of corrected average value between the treatment level of the secretary group and academic group is .827 , which has reached the significance level of .05 . In addition, the difference between the concierge group and the academic group is .617 , between the academic group and the reception group is .674 , and between the academic group and the conference group is .806 . Except that the above groups all reached a significance level of .05 in the pair post hoc, there is no significant difference between the other group pairs. 
Table 5. Post Hoc Table for paired groups

\begin{tabular}{|c|c|c|c|c|c|c|c|c|c|c|c|c|c|}
\hline \multirow[t]{2}{*}{$\begin{array}{c}\text { (I) } \\
\text { Groups }\end{array}$} & \multirow[t]{2}{*}{ (J) Groups } & \multirow{2}{*}{$\begin{array}{c}\text { Average } \\
\text { difference } \\
\text { (I-J) }\end{array}$} & \multirow[t]{2}{*}{$\begin{array}{l}\text { Standard } \\
\text { error }\end{array}$} & \multirow[t]{2}{*}{$\mathbf{P}^{\mathrm{a}}$} & \multicolumn{2}{|c|}{$\begin{array}{l}95 \% \text { confidence } \\
\text { interval of the } \\
\text { difference }^{\mathrm{a}}\end{array}$} & \multirow[t]{2}{*}{$\begin{array}{c}\text { (I) } \\
\text { Groups }\end{array}$} & \multirow[t]{2}{*}{ (J) Groups } & \multirow{2}{*}{$\begin{array}{c}\text { Average } \\
\text { difference } \\
\text { (I-J) }\end{array}$} & \multirow[t]{2}{*}{$\begin{array}{l}\text { Standard } \\
\text { error }\end{array}$} & \multirow[t]{2}{*}{$\mathbf{P}^{\mathrm{a}}$} & \multicolumn{2}{|c|}{$\begin{array}{c}95 \% \text { confidence } \\
\text { interval of the } \\
\text { difference }^{\mathrm{a}}\end{array}$} \\
\hline & & & & & Lower & Upper & & & & & & Lower & Upper \\
\hline \multirow{6}{*}{ त्d } & (1) & .403 & .440 & .367 & -.493 & 1.299 & \multirow{6}{*}{ (્) } & (2) & .423 & .400 & .297 & -.390 & 1.237 \\
\hline & (5) & .194 & .348 & .581 & -.514 & .902 & & $(1$ & $.827 *$ & .386 & .040 & .041 & 1.612 \\
\hline & (7) & .394 & .539 & .470 & -.702 & 1.490 & & (5) & $.617 *$ & .276 & .032 & .056 & 1.178 \\
\hline & (3) & -.423 & .400 & .297 & -1.237 & .390 & & (7) & .817 & .490 & .105 & -.179 & 1.814 \\
\hline & (6) & .251 & .355 & .485 & -.472 & .974 & & (6) & $.674 *$ & .299 & .031 & .065 & 1.283 \\
\hline & (4) & .383 & .335 & .261 & -.298 & 1.065 & & (4) & $.806 *$ & .266 & .005 & .266 & 1.347 \\
\hline \multirow{6}{*}{$\Xi$} & (2) & -.403 & .440 & .367 & -1.299 & .493 & \multirow{6}{*}{ ఏ) } & (2) & -.251 & .355 & .485 & -.974 & .472 \\
\hline & (5) & -.209 & .325 & .523 & -.870 & .451 & & (1) & .152 & .347 & .664 & -.554 & .858 \\
\hline & (7) & -.009 & .518 & .986 & -1.063 & 1.044 & & (5) & -.057 & .218 & .795 & -.500 & .386 \\
\hline & (3) & $-.827 *$ & .386 & .040 & -1.612 & -.041 & & (7) & .143 & .461 & .758 & -.794 & 1.080 \\
\hline & (6) & -.152 & .347 & .664 & -.858 & .554 & & (3) & $-.674 *$ & .299 & .031 & -1.283 & -.065 \\
\hline & (4) & -.020 & .317 & .950 & -.665 & .625 & & (4) & .132 & .203 & .520 & -.282 & .546 \\
\hline \multirow{6}{*}{ (્্) } & (2) & -.194 & .348 & .581 & -.902 & .514 & \multirow{6}{*}{ E } & (2) & -.383 & .335 & .261 & -1.065 & .298 \\
\hline & (1) & .209 & .325 & .523 & -.451 & .870 & & (1) & .020 & .317 & .950 & -.625 & .665 \\
\hline & (7) & .200 & .442 & .654 & -.699 & 1.099 & & (5) & -.189 & .166 & .263 & -.528 & .149 \\
\hline & (3) & $-.617 *$ & .276 & .032 & -1.178 & -.056 & & (7) & .011 & .437 & .981 & -.879 & .900 \\
\hline & (6) & .057 & .218 & .795 & -.386 & .500 & & (3) & $-.806^{*}$ & .266 & .005 & -1.347 & -.266 \\
\hline & (4) & .189 & .166 & .263 & -.149 & .528 & & (6) & -.132 & .203 & .520 & -.546 & .282 \\
\hline \multirow{6}{*}{ త } & (2) & -.394 & .539 & .470 & -1.490 & \multicolumn{8}{|c|}{.702 Depends on the estimated average number of edges. } \\
\hline & (1) & .009 & .518 & .986 & -1.044 & \multicolumn{8}{|c|}{$\begin{array}{l}1.063 \text { a. Adjusted multiple comparisons: the lowest significant } \\
\text { difference (equal to the unadjusted value). }\end{array}$} \\
\hline & $(5)$ & -.200 & .442 & .654 & -1.099 & \multicolumn{8}{|c|}{$.699 *$. The average difference is significant at the .05 level. } \\
\hline & (3) & -.817 & .490 & .105 & -1.814 & .179 & & & & & & & \\
\hline & (6) & -.143 & .461 & .758 & -1.080 & .794 & & & & & & & \\
\hline & (4) & -.011 & .437 & .981 & -.900 & .879 & & & & & & & \\
\hline
\end{tabular}

\subsection{Discussion}

According to the results of the covariate test in this chapter, when the effect of "participation attitude" on cooperative learning effectiveness is removed, the evaluation of cooperative learning effectiveness does not reach a significant level. However, when the "participation attitude" is not removed, the effect is significant. After further exploration, it was found that the comparison of several groups reached a significant level, and the difference was mainly between the academic group and other groups. The cooperative learning effectiveness of the academic group was higher than the secretary group, concierge group, reception group and conference group. This shows that the academic group 
gives the highest evaluation on the activity-oriented course. Relatively speaking, the academic and professional experience gained from the administrative business process related to the thesis can indeed be applied to personal thesis writing in the future. Therefore, the members of this group gave high evaluative feedback.

\section{Conclusion}

\subsection{Division of Labor of Organization Makes Class Cohesive}

Relevant studies indicate that an individual's physical and mental maturity affects the degree of learning initiative (Hsiung, 2012; Lee, 2012). Physically and mentally mature individuals are easier to have empathy, and this situation is also reflected in the learning environment. The students created interpersonal interaction of cooperative learning in the activity-oriented curriculum, which gradually extended to other members of the class and became an invisible sense of mutual identity. The formal class structure formed tacit cooperation among members through administrative management, and integrated interpersonal relations into the implementation of activities in the informal organizational structure, which is also a kind of cohesion in the centripetal force. The participants in this study were master students from two classes. By virtue of the long-standing tradition of mutual assistance in the department, the peer learning model not only achieved the experience inheritance, but also increased the interaction opportunities between the two classes. When there was a harmonious working situation, it could enhance the usefulness of learning from the activity, and affect the self-evaluation of individual's effectiveness in the group. In this study, it was assumed that there was no significant difference in self-evaluation of cooperative learning among labor division groups after excluding the influence of covariates. In other words, the calculated mean values for all groups were similar. From the average figure, it shows that most members give a positive and high evaluation, which may be because the professional division of labor makes the task get half the work with twice the effect. In fact, teachers used the mutual aid method of team organization and cooperation to gather the centripetal force of the class towards the department.

\subsection{The Execution of the Activity Allows Students to Accumulate Experience}

The skill-based education concept attaches importance to practice, learning from doing, experiencing technology, deepening skills and accumulating experience (Hung and Lin, 2014). In addition to the above purposes, the focus of the master's stage also includes more systematic data collation, tests and surveys, empirical response to the literature, practice, the integration of theory and practice. From the literature discussion, this study found that the current way to trigger learners' learning motivation is to use a hands-on method to guide learners to generate curiosity and concentration from the situation of problems. The strategy of combining curriculum with activities is to realize this teaching focus. Students are organized into non-standard classes to carry out the learning tasks set by the course, and to study cooperatively in groups of specialized types. Although it is based on the introduction of situational problems, it can also reduce the number of mistakes with the help from the seniors' experience sharing. For this reason, as the course operation of academic activities enters its second year, the participants gradually master the execution rhythm from experiences, establish and handover the specific work items, and develop specific details of the activities based on the thinking of the discussion, and obtain the opportunity to implement the activities. This verifies the core of master's learning in the integrated curriculum from the experience. The students' reflection on the open questions was a kind of feedback for their practical operations. Most students had a positive attitude and could accept peer and individual reviews. The integration of these data could help to develop an empirical model of problem solving. This is one of the findings of this study.

\subsection{Limitations and Recommendations}

The subjects of this study are mainly master students. After being grouped by major, the number of students in each group did not meet the requirement of quantitative analysis. A longitudinal study design should be used to track and accumulate data over several years to conduct an analysis to identify the main factors affecting cooperative learning in teams and to test the attitudes of different classes towards self-assessment of cooperative learning. In addition, teachers not only need to present research results with measurement data, but also need to use in-depth interviews, observation and retrospection to obtain students' feedback after the implementation of activities, so as to obtain the implicit feelings of the members concerning the course activities. It will help teaching staff to focus on class management, teaching design and understand students' learning reactions from the on-site actions, so as to make the course more flexible and diversified.

\section{References}

Chang, D. R., \& Lin, M. C. (2016). A Study of Effects and Limitations of the Application of Problem-Based Learning on a Student Teaching Curriculum. Journal of Teacher Education and Professional Development, 9(2), 
1-25. https://doi.org/10.3966/207136492016080902001

Chang, F. Y. (2016). An Exploration of Project-based Engineering Design Curriculum in Senior High School. Technology and Human Resources Education Quarterly, 3(1), 5-11. https://doi.org/10.6587/jthre.2016.3(1).2

Chang, J. C., Lin, K. M., Peng, I. W., \& Chou, C. F. (2017). An Application of Inquiry Teaching to the Practical Project Course Influences University Students' Inquiry Ability and Creative Thinking Ability in Relative Department of Electrical Engineering and Computer Science. Journal of Technology and Engineering Education, 48(2), 17-43.

Cheng, H. L. (2002). A Study on High School Students' Attitude and Behavior of Civic Participation: A Case Study of Taipei City Public High Schools. Bulletin of Civic and Moral Education, (11), 233-249. https://doi.org/10.6231/cme.2002(11)10

Cheng, L. Y., Chiu, W. H., \& Tseng, T. M. (2014). The Influence of Cooperative Learning on Gymnastics Learning Performance. Physical Education Journal, 47(1), 129-138. https://doi.org/10.6222/pej.4701.201403.1211

Chiang, S. B. (2015). Case Study and Perspective Reflection for the Practice of Graduation Project of Design Department. Journal of National Taiwan College of Arts, (97), 43-74.

Chiu, A. L. (2003). An Analysis of Integrative Activities Textbooks from Hidden Curriculum Perspectives. Curriculum \& Instruction Quarterly, 6(4), 37-59+185. https://doi.org/10.6384/ciq.200310.0037

Chou, W. H. (2018). Teaching Effectiveness of Adopting the World Café Model to Promote College Students' Civic Participation. Journal of Research in Education Sciences, 63(3), 37-67. https://doi.org/10.6209/jories.201809_63(3).0002

Hu, X., Chen, J., \& Wang, Y.(2021). University students' use of music for learning and well-being: A qualitative study and design implications. Information Processing \& Management, 58(1), 102409. https://doi.org/10.1016/j.ipm.2020.102409

Huang, Z. D. (2011). Optimize the Form of Class Organization to Realize the Independence of Students. New Curriculum Learning $\cdot$ Midmonth, 187-188.

Hung, C. H., \& Lin, C. Y. (2014). Efficiency and Implications of Problem-Based Learning on Clinical Competence in Medical Education. Chinese Journal of Science Education, 22(1), 1-32. https://doi.org/10.6173/cjse.2014.2201.01

Kao, C. C. (2012). A Study on Influences from Student Team Achievement Division to Basketball Strategy Cognition and Learning Motivation. Journal of Taiwan Sport Pedagogy, 7(2), 23-40. https://doi.org/10.6580/jtsp.2012.7(2).02

Kao, C. S. (2003). Application of Cooperative Learning in Class Management. Taiwan Education Review, (624), 62-64. https://doi.org/10.6395/ter.200312.0062

Kuo, C. H. (2000). A Case Study of the Homeland Education Activities Curriculum Transition of Elementary Schools. Curriculum \& Instruction Quarterly, 3(3), 49-72+164. https://doi.org/10.6384/ciq.200007.0049

Le Bail, C., Baker, M., \& Détienne, F.(2020).Values and argumentation in collaborative design. CoDesign, 1-21. https://doi.org/10.1080/15710882.2020.1782437

Lee, S. S. (2012). The Influence of Grade Difference on the Maturity of Medical College Students' Career. Campus Life \& Mental Health, 238-240.

Meng, Y. (2011). Class Cadres and Informal Groups in Class. Ideological \& Theoretical Education (second semimonthly), 41-45.

Rui, H. L. (2013). Research on the Current Situation and Countermeasures of College Class Organization. Modern Enterprise Education, 102-103.

Su, Y. L., \& Chen, L. C. (2007). The Effect of Sociometric Status, Cooperative Learning, and Traditional Learning among Junior High Students on English Academic Performance, Social Anxiety, Achievement Motivation, and Attribution. Bulletin of Educational Psychology, 39(1), 111-127.

Suo, G. F., \& Ren, H. Y. (2006). Construction of the Teaching Model of Collaborative Learning in the New Curriculum System. Curriculum, Teaching Materials, Teaching Methods, 8.

Tang, Y. (2012). Development and Reliability and Validity Test of Cooperative Learning Questionnaire for Senior 
High School Students [unpublished, master's thesis]. Department of Developmental and Educational Psychology, Sichuan Normal University.

Uzun, A., Onur, A., \& Alabay, S.(2020). Students' views on database management systems course designed according to problem-based learning. International Journal of Evaluation and Research in Education, 9(1), 177-187. https://doi.org/10.11591/ijere.v9i1.20501

Wang, B. C. (2015). Chinese Window SPSS and Behavioral Science Research. Psychological Publishing.

Wang, H. M. (2016). Experience and Reflection on the Application of Cooperative Learning in Physics and Chemistry Teaching of Junior High Schools. Taiwan Educational Review Monthly, 5(3), 130-132.

Wu, J.-Y., \& Nian, M.-W. (2021). The dynamics of an online learning community in a hybrid statistics classroom over time: Implications for the question-oriented problem-solving course design with the social network analysis approach. Computers \& Education, 166, 104-120. https://doi.org/10.1016/j.compedu.2020.104120

Wu, Y. F. (2015). My views on the Cultivation of Class Cohesion. Education Monthly (Primary Edition), 48-49.

Zhou, Y. B., \& Luo, W. Y. (2010). Reflections on the Strata Differentiation in Class Organization -- From the Perspective of Class Cadre Selection. Modern Education Science (Middle School Teacher), 59-60.

\section{Copyrights}

Copyright for this article is retained by the author(s), with first publication rights granted to the journal.

This is an open-access article distributed under the terms and conditions of the Creative Commons Attribution license (http://creativecommons.org/licenses/by/4.0/). 